\title{
Corrigendum
}

\section{Corrigendum to "Synthesis and Characterization of Fibre Reinforced Silica Aerogel Blankets for Thermal Protection”}

\author{
S. Chakraborty, ${ }^{1}$ A. A. Pisal, ${ }^{2}$ V. K. Kothari, ${ }^{1}$ and A. Venkateswara Rao ${ }^{2}$ \\ ${ }^{1}$ Department of Textile Technology, IIT, New Delhi 110016, India \\ ${ }^{2}$ Air Glass Laboratory, Department of Physics, Shivaji University, Kolhapur, Maharashtra 416 004, India \\ Correspondence should be addressed to A. Venkateswara Rao; avrao2012@gmail.com
}

Received 23 November 2016; Accepted 28 November 2016; Published 12 January 2017

Copyright (C) 2017 S. Chakraborty et al. This is an open access article distributed under the Creative Commons Attribution License, which permits unrestricted use, distribution, and reproduction in any medium, provided the original work is properly cited.

In the article titled "Synthesis and Characterization of Fibre Reinforced Silica Aerogel Blankets for Thermal Protection" [1], there was an error in the Introduction, which should be corrected as follows:

Reference 11 by Shaid et al. was cited to support the statement "Aerogel nanoparticle coated fabrics for firefighting applications were found to have increased thermal resistance, good air permeability, and moisture management properties." However, that article stated that an aerogel coating on fabric reduces air permeability and did not state that aerogels have good moisture management properties. In our work, we found that as well as residing on the surface of the fabric some aerogels get into the interstices of the fabric, which may increase air permeability.

\section{References}

[1] S. Chakraborty, A. A. Pisal, V. K. Kothari, and A. Venkateswara Rao, "Synthesis and characterization of fibre reinforced silica aerogel blankets for thermal protection," Advances in Materials Science and Engineering, vol. 2016, Article ID 2495623, 8 pages, 2016. 

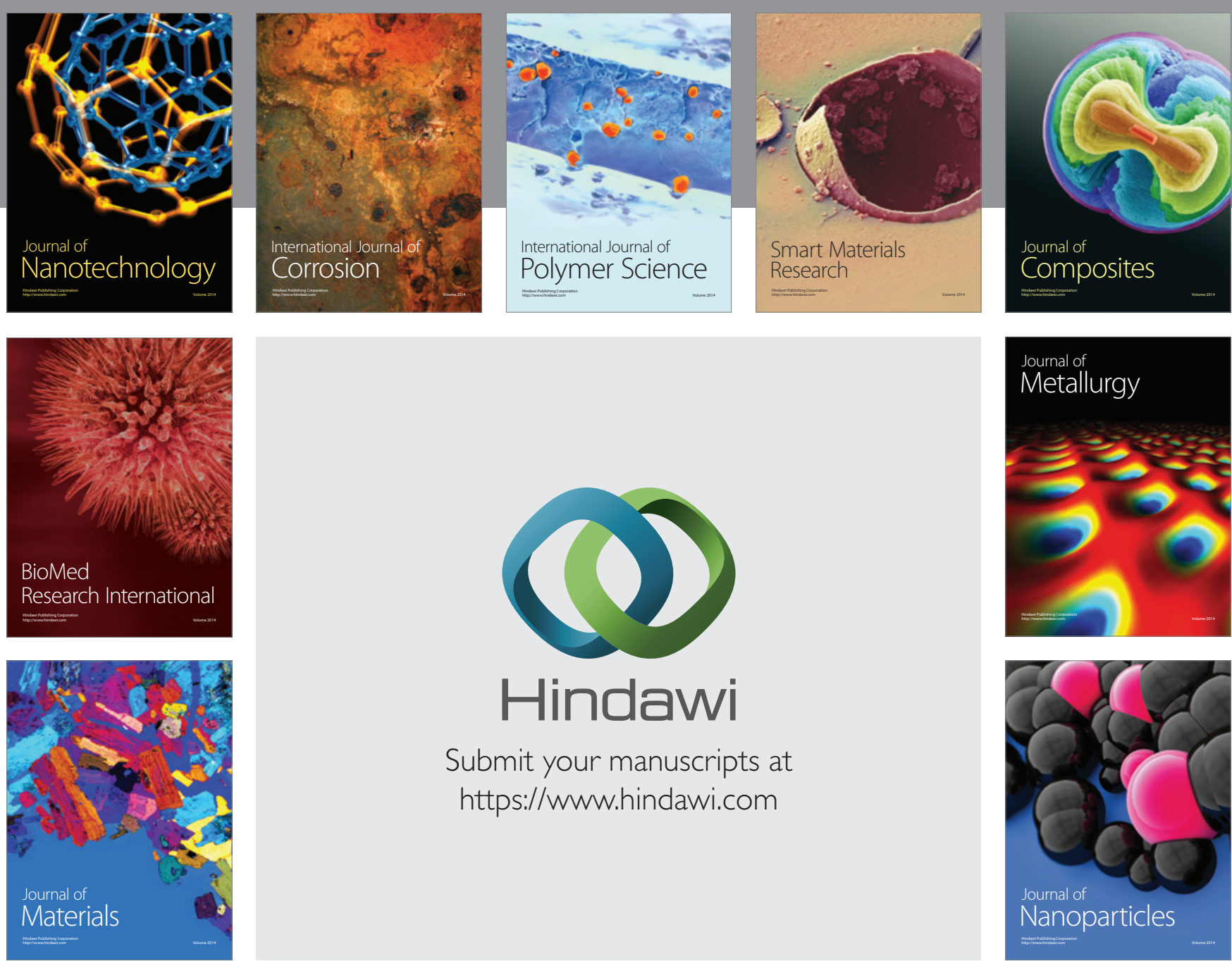

\section{Hindawi}

Submit your manuscripts at

https://www.hindawi.com

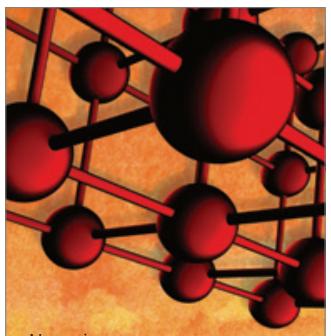

Materials Science and Engineering
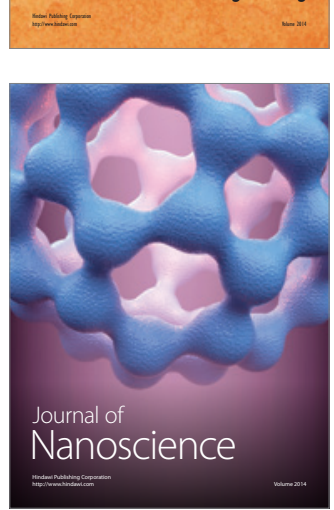
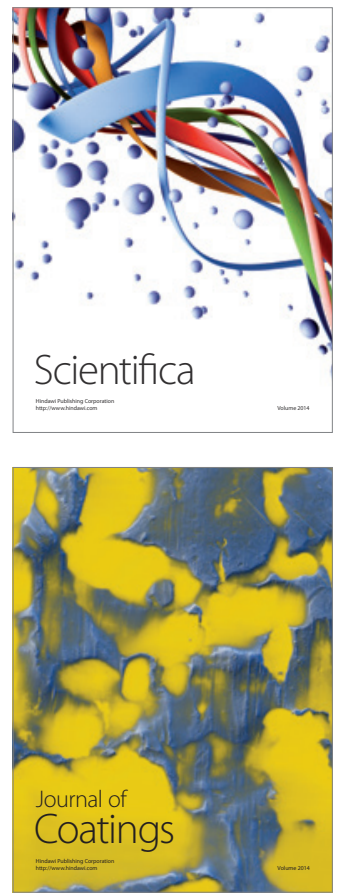
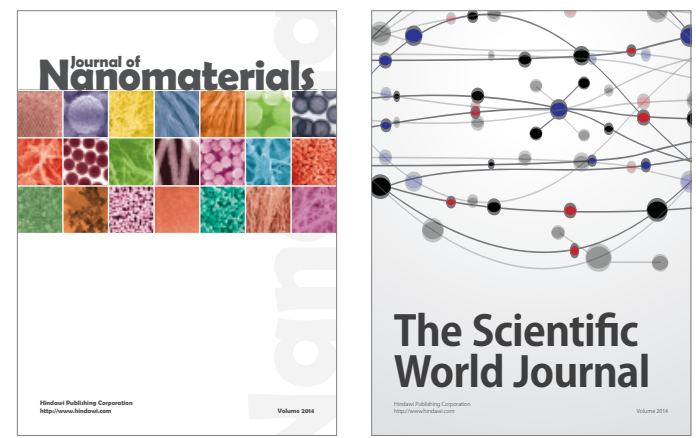

The Scientific World Journal
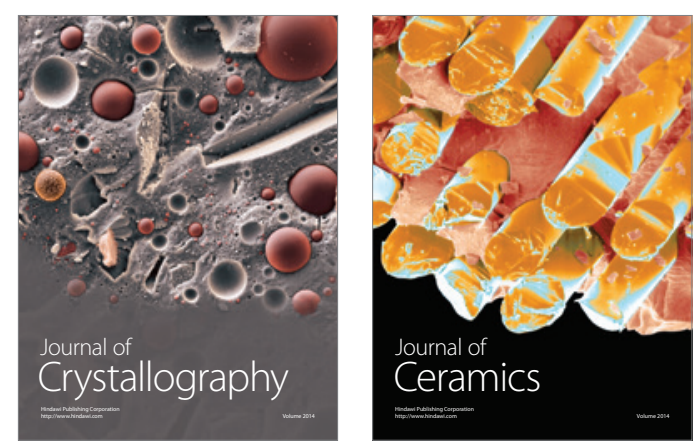
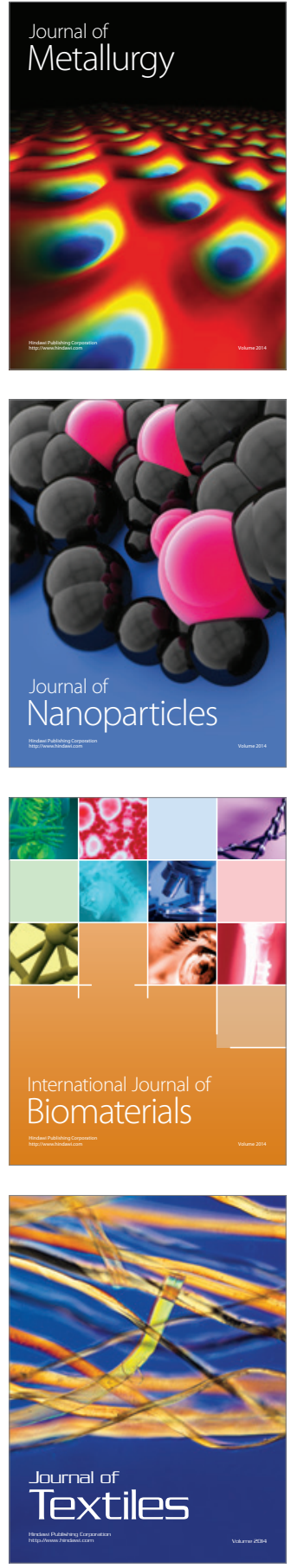